\title{
Continuous Set Periodic Hull Data Type
}

National Cancer Institute

\section{Source}

National Cancer Institute. Continuous Set Periodic Hull Data Type. NCI Thesaurus. Code C95641.

A data type comprised of the periodic lull between sets of unordered, quantitative values. 